Book review

\title{
Simon O'Sullivan, On the production of subjectivity: Five diagrams of the finite-infinite relation
}

\section{Palgrave Macmillan, 2012, ISBN: 978-0-230-24980-6}

With the publication of the On the production of the subjectivity, Simon O'Sullivan delivers to the contemporary thought on the subject a wide scope of theoretical possibilities of subjectivity production, explained through a series of highly descriptive diagrams that integrate various models relevant for political potentialities towards a non-capitalist mode of such production. The return to the question of the subject as undertaken by O'Sullivan is one that evades the object-subject opposition in favor of a philosophy that acts simultaneously as speculative thought process but also as a pragmatic undertaking that informs a way of life. The enquiry that this book provides is a diagrammatic move towards a production of subjectivity which always already precedes the subject as a fixed entity and poses itself in an open confrontation against the capitalist subjection. It is this site, of the subject, that O'Sullivan following Felix Guattari declares to be the locus of the struggle against the capitalist homogenization, reduction and standardization. The opening of the finite being towards the infinite as its resource, represents a major political challenge of On the production of the subjectivity in its specific non-theological claim of the finite-infinite relation that opposes capitalism's tendency to exploit all potential for production of subjectivity.

In the challenge to locate the subject in the finite-infinite relation, which results as an effect of the process of subjectivity production, O'Sullivan adopts a Deleuzean approach, focusing on the non-hierarchical and non-fixated state of the subject, allying himself to Deleuze's mode of production against Badiou's principle of fidelity. O'Sullivan's On the production of the subjectivity delivers five diagrams of the finite-infinite relation through a series of works of the most important philosophers of the subject including Spinoza, Nietzsche, Bergson, Foucault, Lacan, Badiou and finally concluding with the works Deleuze and Guattari that serve as a philosophical bedrock for O'Sullivan's investigation into the modes of production of subjectivity.

The book begins with the construction of O'Sullivan's basic diagram of the finite-infinite relation that is a composition resulting from Spinoza's three kinds of knowledge, Nietzsche's affirmation and eternal return and Bergsons mater and memory. To the specific ideas of the three thinkers, O'Sullivan employs Deleuze and Guattari's thoughts in order to trace the similarities and to integrate them into one coherent diagram of the process of production of subjectivity. Further, he constructs, through Nietzsche and Spinoza the argument against the passive, reactive subject of capitalism as a results of a subjectivity produced by a transcendent operator, which in our times all the more is being identified with Capital. In that sense, O'Sullivan introduces the optimism and the call to creativity, to creation against reaction and in opposition to the morality steaming of any kind of transcendent authority.

Further on, O'Sullivan immediately reveals the political aim of the book against the capitalist production of the subject which in the words of Lacan works in the 'service of goods' and reveals the revolutionary potential of desire which is unpredictable, non-productive and unconscious and thus upsets any morality, which as such nowadays is traced to the protestant logic of austerity in the times of crisis in Europe. The price to be paid for ones following of his or hers desire is a form of betrayal that acts as a form of a non-capitalist mode of production of subjectivity via the desire. In Foucault's 'Care for the Self', O'Sullivan locates the mode of the finite-infinite relation in the 'idea that the access to truth must involve a prior preparation by the subject who is then in turn, transformed by that very truth'.

Guttari's ontology receives a special attention of O'Sullivan in which he stresses out the importance of the aesthetic paradigm to the contemporary field of creative life practices. In elaborating Guattari's genuine concept of chaosmosis O'Sullivan gives us a profound explanation:

Chaosmosis contains the most condensed and worked out statement of Guattaris very particular and complex schizoanalytic cartography. It also operates itself as a machine of sorts: a grasping and gathering of different materials that might be mobilized in the general project forming an ontology 'beyond' the subject-object split and, leading on from this, of constructing a form of institutional analysis beyond Lacan. (111)

To the thought of Guattari and Deleuze and their collaborative works, the author ascribes the diagramming of a new relation of the finite and the infinite. Thus the author throughout the book traces the inconsistencies in other thinker's modes of production of subjectivity while trying simultaneously to find points of diagrammatic convergence, a gesture 
that amounts to an event in the theory of the subject. In that move, O'sullivan contests Badiou's claim that truth is one of inconsistent multiplicities and masterfully point out the problem of the remaining gap between the finite and the infinite, or the event and the subject, which necessitates a heroic subject, one which is barred from an infinite that has nevertheless called them into action.

Having praised the return of the speculative though on the subject, the author also takes a close investigation in the pragmatic aspects of production of subjectivity in Deleuze and Guattaris $A$ Thousand Plateaus, focusing on the practical organization of subjectivity against the dominant forms of subjection enacted by the operations of Capital. Speculation is indeed not only a metaphysical operation of thought, it is rather a move from the perspective of the subject towards accessing the 'outside', which amount to a particular kind of practice that requires experimentation. On the production of the subjectivity is a endeavor of rigorous theoretical construction and affirmation of the author's political claim to a mode of production of subjectivity beyond capitalism, one that finds traces of fidelity to its proclaimed idea through a complex inquire into the works of the most prominent thinkers of the subject.

\section{Artan Sadiku}

